\title{
Social theory in mathematics education: Guest editorial
}

\author{
Candia Morgan
}

Published online: 23 August 2014

(C) Springer Science+Business Media Dordrecht 2014

The articles in this Special Issue arose originally from the work of the Research Forum on Sociological Frameworks in Mathematics Education Research at the conference of the International Group for the Psychology of Mathematics Education (PME) in 2009. The acceptance of this Research Forum at PME was indicative of the shift within mathematics education research during the last two decades involving what has been called the "social turn" (Lerman, 2000). Researchers concerned with a wide variety of issues within mathematics education have come increasingly to see the inseparability of culture, context and cognition. Even within research that focuses primarily on cognitive aspects of learning and knowledge, notions of situated learning and distributed knowledge (Lave \& Wenger, 1991) are widely used, as well as other theoretical perspectives that emphasise social aspects of learning, drawing in particular on Vygotskian psychology (Vygotsky, 1978).

Moving beyond seeing mathematics learning solely as the endeavour of individual students and teachers has been reflected in a broader conceptualization of the subject matter of the field of mathematics education research. Valero (2010) has drawn our attention to the complexity of the networks of communities, interest groups and practices relevant to mathematics education and to the need for research to address this multiplicity of social practices and the connections between them. We are thus aware of the importance of studying the various communities and practices in which students and teachers participate, both within the classroom and beyond. We recognise the influence of policy and institutional structures and constraints at local, national and international levels. We appreciate the impact of the various discourses available inside and outside the school - discourses in the sense written with a capital D by Gee (1996) and defined as incorporating "theories" about what is normal and right and structuring the kinds of identities available to participants.

This increasing attention to social aspects of learning has been accompanied by a growth in research foregrounding issues of social justice. Differing levels of achievement in mathematics in particular as well as in education as a whole have been associated with membership of various social groups and the effects of such factors as gender, ethnicity, class and linguistic background on the achievement of students in school mathematics have long been a focus of study. However, our ways of understanding the phenomenon of school failure have developed. In particular, there has been a move from locating the reasons for failure in the characteristics of the individuals concerned or of their communities towards seeking to understand how the

C. Morgan $(\bowtie)$

Department of Curriculum, Pedagogy and Assessment, Institute of Education, University of London, 20

Bedford Way, London WC1H 0AL, UK

e-mail: c.morgan@ioe.ac.uk 
practices and structures of the education system itself, as well as the broader society and its dominant discourses, serve to construct and sustain disadvantage (e.g., Herbel-Eisenmann, Choppin, Wagner, \& Pimm 2012). At the same time, many researchers seek to go beyond a focus only on conventional educational outcomes as indicators of success or failure, seeing identity, social recognition and participation as equally important dimensions of social justice (e.g., Black, Mendick, \& Solomon 2009). Social justice is a significant concern to the authors in this Special Issue. In some cases, it is the major focus of research, in others, it forms a background to the discussion of other issues.

Recent profound changes within the global world economy and accompanying developments in hegemonic discourses have impacted strongly on mathematics education as well as on other areas of human endeavour. New emphases on efficiency, mobility, and new orders of digital information and communications technology have transformed expectations and created new demands for cultural and social change. The expectation that people should participate in life-long learning has arisen from the growing instability of the labour market and its changing demands. At the same time, marketisation of education has affected the ways in which educational institutions operate and new conceptualisations have developed the roles of students, teachers, communities and the relationships between them (Apple, 2005). Discourses of accountability have led to a plethora of measurements of educational outcomes, affecting the practices and relationships of students and teachers across all levels of education-as well as the practices of researchers (Biesta, 2004; Lucas, 2006).

While these developments have carried significant challenges across all arenas of society, within mathematics education, they have arguably been felt most strongly through the agency of national policies around curriculum and assessment, in the professional formation of teachers and in the advent of international systems of assessment such as the Programme for International Student Assessment (PISA) and the Programme for the International Assessment of Adult Competencies (PIAAC). The perceived significance of mathematics for technological and economic competitiveness and the gate-keeping role played by mathematics in the distribution of educational and employment opportunities and hence of societal resources mean that international and national policy developments attend more directly to mathematics education and performance than is the case for some other subject areas. In the UK, for example, we have seen increased direct intervention from government in mathematics education, looking to the perceived educational and economic success of jurisdictions such as Singapore and Shanghai in order to propose the importation of changes to curriculum content and pedagogy (e.g., Department for Education \& Truss 2014). Such global trends and national policies have significant implications for classroom practice, the mathematical experiences of students at all levels and the professional lives of teachers as they impact on the kinds of mathematics in the curriculum and the valued forms of assessment and of pedagogy. They thus form a background to all areas of education and are a major focus of research for some of the contributors to this Special Issue; articles by Kanes, Morgan and Tsatsaroni and by Tsatsaroni and Evans analyse and critique the international testing regimes that increasingly influence national education policies and curricula, focusing on PISA and PIAAC, respectively, while Lerman sets the national regulatory apparatus for teacher education in the UK within this global context.

In striving to address such concerns and to take account of their complex nature, the mathematics education research community has drawn on a wide range of theoretical and methodological approaches. This variety of theoretical resources is perhaps inevitable within a multidisciplinary field such as mathematics education and much is to be gained from the contributions of different perspectives. There is a danger, however, of "cherry-picking" ideas from theories arising within diverse disciplines such as sociology, psychology, philosophy or 
anthropology without following through, reflecting upon and developing the implications of the theoretical frameworks within which the ideas were originally situated (Lerman, 2006). While the use of an isolated theoretical construct can lead to useful insights, its explanatory and predictive power tends to be limited and it is unlikely to provide adequate support for action to effect change. At the same time, in adopting theoretical resources developed in other fields, there is a danger of displacing mathematics from its central place in our concerns. The authors contributing to this Special Issue share a belief that it is essential to maintain the centrality of mathematics in our research and to develop our understanding of how the place of mathematical knowledge may be conceptualized using such theoretical resources and how these can help us to address fundamental issues in our field.

The choice by researchers of theoretical approaches and methodological tools is not arbitrary. It is, of course, shaped not only by the nature of the objects of concern but also by the interests, knowledge and experience of the researcher and by the traditions and expectations of the environment within which they are situated (Lagrange \& Kynigos, 2014). However, the relationship between choice of theory and object of study may be seen as dialectical: a particular theoretical lens not only allows us to address issues that have been identified as being of concern but also affects the way we perceive and define these issues and may raise new issues that were previously unthinkable. In the case of social theories, we are led to perceive the characteristics, actions and achievements of individual students, teachers and other participants as phenomena arising within social practices, structures and discourses. Studying those practices, structures and discourses allows us to gain new insights into the experiences of individuals.

This Special Issue seeks to focus on one area of this complex theoretical landscape by bringing together a collection of articles that will help to develop a fuller understanding of the contribution that social theories can make to work in mathematics education research. Within the space available, it is not possible to do justice to the full range of thinking in the field of social theory; the articles collected here draw mainly on the social theories of Bernstein, Foucault and Bourdieu. These theories are all widely used within educational research, though their impact within mathematics education is still limited. Importantly, they allow us to address issues of knowledge - its construction, distribution and social role - and questions about how social practices affect individuals - the formation of their identities and their possibilities for participation and success or failure.

Bernstein's work is fundamentally concerned with the functioning of education, providing an approach to considering how knowledge is transmitted, transformed, distributed and evaluated in pedagogic settings (e.g., Bernstein, 2000). Within mathematics education, Bernsteinian constructs have been used by researchers including Dowling (1998), Cooper and Dunne (1998) and Straehler-Pohl and Gellert (2013) to understand how access to successful participation in mathematics schooling is distributed across different social groups. Some of Bourdieu's work also addresses educational contexts directly (e.g., Bourdieu \& Passeron, 1990), though his theoretical tools, including those of social and cultural capital, habitus and field, are more generally applicable to interrogate and understand relationships between individuals and social structures (Bourdieu, 1990). His impact on educational research has been most extensive in higher education research, though, within mathematics education, some of his theoretical constructs have been used to explore such issues as conflicts experienced in teacher education (Nolan, 2012), the practices and positioning of new teachers (Noyes, 2004) and the mechanisms by which children are positioned socially during the transfer from primary to secondary school (Noyes, 2003).

While Foucault himself did not focus specifically on education, his introduction of the notion of discursive formation and his conceptualization of knowledge-power (Foucault, 1972) 
have been immensely influential both within educational thinking (e.g., Popkewitz \& Brennan, 1998) and, more widely, underpinning much of the development of post-structuralist and postmodern thinking. Within mathematics education, Foucault has especially informed thinking on gender issues, starting from the seminal work of Valerie Walkerdine (1988) and developed more recently by authors such as Walshaw (2001), as well as studies that seek to illuminate power relations in mathematics classrooms (e.g., Hardy, 2004). In this Special Issue, some of Foucault's later thinking on governmentality (Foucault, 1991) is used as a means of understanding the relationship between the self and the state.

In order to engage with readers who are unfamiliar with these theories, the articles provide an introduction to some key theoretical ideas. Most importantly, however, the authors seek to demonstrate what the theories can offer to the study of mathematics education, focusing on significant issues of interest to the field. The articles range across a variety of objects of study, including international assessments, national policies, teacher education, school practices and classroom interaction, engaging with the global issues described above in ways that are directed by the problems and contexts of mathematics education. Overall, the authors seek to explore how social-theoretical frameworks can and do inform research in mathematics education, how they can generate new research questions as well as address existing research areas in new ways, and how they can point towards ways in which more equitable outcomes may be achieved.

They do not simply apply these theories but also combine or develop them and develop new methodological approaches, strongly founded in social theory, that enable us to address pressing issues in mathematics education. In particular, the articles by Tsatsaroni and Evans, by Lerman and by Kanes et al. argue for the need to draw on ideas from the theories of both Bernstein and Foucault in order to look at interactions between international and national policy and practice and their effects on identity formation for students and teachers of mathematics. Within the context of a study of teacher education in South Africa, Parker and Adler start from Bernsteinian theory in order to develop a new way of looking at the knowledge produced in teacher education classes. Jorgensen, Gates and Roper address the extensively studied practice of “ability grouping”, using Bourdieu's notions of habitus and field to critique and challenge the assumptions underpinning this practice.

The question of choice of theory is addressed directly by Morgan in the first article. Once we recognise that learning and teaching mathematics are not entirely individual activities, it is necessary to find ways of studying and understanding not only the discrete phenomena that we experience and observe directly but also the ways in which these phenomena are situated within and shaped by social practices and structures. Using the device of a narrative of her own trajectory as a researcher, Morgan demonstrates how, in combination with linguistic and discursive theories, Bernstein's social theory provides her with theoretical tools for studying and understanding some of the complex phenomena that are the objects of mathematics education research. In particular, the notion of recontextualisation is applied to the analysis of curriculum documents and to examples of classroom pedagogy.

The articles by Lerman and by Kanes et al. both locate their studies in relation to national and international policies and the regulation of practices of mathematics education, drawing on the theoretical constructs of Bernstein and of Foucault. Arguments are presented by these authors that, while Bernstein enables analysis of structural relationships between official and unofficial discourses and of the form of pedagogic discourses, Foucault's notions of subjectification and governmentality provide a means of understanding how identities may be formed within the framing of these discourses by teacher educators, teachers and students. Lerman's study focuses on the regulation of teacher education in England, examining how a regime of inspection and self-evaluation has affected the ways that teacher educators may conceive of their role. Kanes et al. propose a methodology for investigating the effects of 
international testing regimes, taking PISA as an example and illustrating their methodology with analysis of a PISA test item. Tsatsaroni and Evans also address international testing regimes, in this case looking at assessments of adult "numeracy". They raise some methodological issues about the conduct and analysis of the tests and provide a strong critique of the model of knowledge construed by regimes such as PISA and PIAAC.

Bernstein's theory of pedagogic discourse is again used by Parker and Adler as a means of analysing the practices of mathematics teacher education in South Africa. The authors use this theory to develop new analytic tools in order to enable a description of the specialised forms of knowledge of mathematics and of teaching (and, hence, knowledge of mathematics for teaching) that are produced in these practices and to illuminate the processes by which this knowledge is produced.

One of the consequences of adopting a social perspective is a recognition that success and failure in school mathematics do not result solely from individual students' strengths or deficiencies but are systematically associated with social disadvantage. Jorgensen et al. provide an account of how Bourdieu's theory of habitus and field helps us to understand the systemic failure of disadvantaged students and communities and to see how practices in mathematics education serve to exert and maintain power relations. The authors present case studies of two school students, demonstrating how the habitus each has developed in the context of their family and social class environment affects their possibilities for action and success in learning mathematics within the school environment.

One critical question sometimes posed to researchers in mathematics education who are concerned with social issues and social justice is as follows: "where is the mathematics?" In this Special Issue, a major focus of many of the articles is mathematical knowledge: What kind of mathematical knowledge is being produced by the policies and practices investigated? How is mathematical knowledge produced in these practices? How is mathematical knowledge distributed? At the same time, the authors are concerned with how students, teachers and teacher educators experience mathematics, learning and teaching and how their identities may form in relation to these practices. These issues are all of central concern to the field of mathematics education. Yet, they are challenged by the final article in this issue: a commentary provided by Valero and Pais that calls into question the practices of researchers in mathematics education. These authors argue that, by valorising mathematics itself, researchers contribute to the constitution of its privileged place in society and the uses to which it is put as a gatekeeper and as a means of reproducing social inequalities. This challenge poses a fundamental problem for mathematics education researchers. Our own professional identities and, in many cases, our conditions of employment are highly dependent on our commitment to mathematics and on the privileged position of mathematics in society. Rejecting or even critiquing this position places considerable demands on researchers that will require further work to resolve.

The articles collected here demonstrate how social theory provides theoretical and methodological tools that can provide important insights into core concerns of mathematics education and can challenge some of the taken-for-granted practices and discourses of our field. They also show that addressing the specific problems of mathematics education demands thoughtful selection and development of these tools. We do not claim to do more than illustrate the power and relevance of adopting theoretical positions that are strongly informed by social theory. Yet, we hope these illustrations can offer a resource to enable mathematics education researchers to engage further with the theoretical perspectives discussed here and with other perspectives that provide ways of understanding how individual experience is related to wider social practices and structures. 


\section{References}

Apple, M. W. (2005). Education, markets, and an audit culture. Critical Quarterly, 47(1-2), 11-29. doi:10.1111/j. 0011-1562.2005.00611.x.

Bernstein, B. (2000). Pedagogy, symbolic control and identity: Theory, research and critique. Lanham: Rowman and Littlefield.

Biesta, G. J. J. (2004). Education, accountability, and the ethical demand: Can the democratic potential of accountability be regained? Educational Theory, 54(3), 233-250. doi:10.1111/j.0013-2004.2004.00017.x.

Black, L., Mendick, H., \& Solomon, Y. (Eds.). (2009). Mathematical relationships in education: Identities and participation. London: Routledge.

Bourdieu, P. (1990). The logic of practice. Oxford: Blackwell.

Bourdieu, P., \& Passeron, J.-C. (1990). Reproduction in education, society and culture (2nd ed.). London: Sage.

Cooper, B., \& Dunne, M. (1998). Social class, gender, equity and National Curriculum tests in mathematics. In P. Gates (Ed.), Proceedings of the First International Mathematics Education and Society Conference (pp. 132-147). Nottingham: Centre for the Study of Mathematics Education, Nottingham University.

Department for Education, \& Truss, E. (2014). Experts to visit Shanghai to raise UK maths standards [Press release]. Retrieved from http://www.gov.uk/government/news/experts-to-visit-shanghai-to-raise-standards-in-maths

Dowling, P. (1998). The sociology of mathematics education: Mathematical myths/pedagogic texts. London: Falmer.

Foucault, M. (1972). The Archaeology of Knowledge (A. M. Sheridan Smith, Trans.). London: Routledge.

Foucault, M. (1991). Governmentality. In G. Burchell, C. Gordon, \& P. Miller (Eds.), The Foucault effect (pp. 87-104). Chicago: University of Chicago Press.

Gee, J. P. (1996). Social linguistics and literacies: Ideology in discourses (2nd ed.). London: Taylor \& Francis.

Hardy, T. (2004). "There's no hiding place". Foucault's notion of normalization at work in a mathematics lesson. In M. Walshaw (Ed.), Mathematics education within the postmodern (pp. 103-119). Information Age: Greenwich.

Herbel-Eisenmann, B., Choppin, J., Wagner, D., \& Pimm, D. (Eds.). (2012). Equity in discourse for mathematics education. Dordrecht, Netherlands: Springer.

Lagrange, J.-B., \& Kynigos, C. (2014). Digital technologies to teach and learn mathematics: Context and recontextualization. Educational Studies in Mathematics, 85(3), 381-403. doi:10.1007/s10649-013-9525-z.

Lave, J., \& Wenger, E. (1991). Situated learning: Legitimate peripheral participation. Cambridge: Cambridge University Press.

Lerman, S. (2000). The social turn in mathematics education research. In J. Boaler (Ed.), Multiple perspectives on mathematics teaching and learning (pp. 19-44). Westport, CT: Ablex.

Lerman, S. (2006). Theories of mathematics education: Is plurality a problem? Zentralblatt für Didaktik der Mathematik, 38(1), 8-13. doi:10.1007/BF02655902.

Lucas, L. (2006). The research game in academic life. Maidenhead: Open University Press and the Society for Research in Higher Education.

Nolan, K. (2012). Dispositions in the field: Viewing mathematics teacher education through the lens of Bourdieu's social field theory. Educational Studies in Mathematics, 80(1-2), 201-215.

Noyes, A. (2003). School transfer and social relocation. International Studies in Sociology of Education, 13(3), 261-280. doi:10.1080/09620210300200113.

Noyes, A. (2004). (Re)producing mathematics educators: A sociological perspective. Teaching Education, 15(1), 243-256.

Popkewitz, T., \& Brennan, M. (Eds.). (1998). Foucault's challenge: Discourse, knowledge, and power in education. New York: Teachers College Press.

Straehler-Pohl, H., \& Gellert, U. (2013). Towards a Bernsteinian language of description for mathematics classroom discourse. British Journal of Sociology of Education, 34(3), 313-332.

Valero, P. (2010). Mathematics education as a network of social practices. In V. Durand-Guerrier, S. SouryLavergne, \& F. Arzarello (Eds.), Proceedings of the Sixth Congress of the European Society for Research in Mathematics Education (pp. LIV-LXXX). Lyon: Institut National de Rechérche Pédagogique.

Vygotsky, L. (1978). Mind in society: The development of higher psychological processes. Cambridge: Harvard University Press.

Walkerdine, V. (1988). The mastery of reason: Cognitive development and the production of rationality. London: Routledge.

Walshaw, M. (2001). A Foulcauldian gaze on gender research: What do you do when confronted with the tunnel at the end of the light? Journal for Research in Mathematics Education, 32(5), 471-492. 